\title{
A Study on Beta-Glucuronidase Enzyme as a Probable Biomarker in Cases of Acute Poisoning by Cholinesterase Enzyme Inhibitor Insecticides
}

\author{
Manal H. Abd El-Aziz ${ }^{1}$,Gehan Sharara², Asmaa S. El-Banna', and Shawky S. \\ El-Naggar3
}

\author{
${ }^{1}$ Department of Forensic Medicine and Clinical Toxicology, Faculty of Medicine, Alexandria University \\ ${ }^{2}$ Department of Biochemistry, Faculty of Medicine, Alexandria University \\ ${ }^{3}$ Emergency Medicine, Al-Ameria General Hospital \\ Alexandria, Egypt.
}

\begin{abstract}
Acute poisoning by cholinesterase enzyme inhibitors insecticide continues to be a detrimental problem and a potential cause of mortality especially in developing countries. Early intervention in such cases is proven to be helpful. The aim of the present work was to assess the role of serum $\beta$-glucuronidase level as probable marker for the assessment of acute cholinesterase enzyme inhibitors insecticides poisoning. Subjects and methods: the study included 60 cases of acute poisoning by cholinesterase enzyme inhibitors insecticides, admitted to the Poison unit of Alexandria Main University Hospital, another 15 healthy volunteers were included as control group. All the cases were subjected to: thorough history taking, full clinical examination, grading of poisoning severity score (PSS), laboratory investigations (serum cholinesterase activity level (CHE) and serum $\beta$-glucuronidase level $(\beta G)$. Results: Serum CHE levels were significantly decreased, while Serum $\beta G$ were significantly increased in the patients compared with the controls, and also, with increasing severity of poisoning. A significant negative correlation was detected between level of serum CHE and duration of hospitalization, while a significant positive correlation was found between serum level of $\beta G$ and length of hospital stay. In addition, a significant inverse correlation was found between levels of $\mathrm{CHE}$ and $\beta \mathrm{G}$ whether in control group or in cases. Data obtained from ROC curve analysis revealed that serum $\beta$ Glevel was more helpful in diagnosis of OP poisoning than CHE (accuracy $100 \%$ versus $80 \%$ ), while both serum CHE and $\beta$ G levels were of equal accuracy percentage for detection of poisoning severity and for prediction of outcome (100\% and $91.67 \%$ each). Conclusion: Serum $\beta \mathrm{G}$ could be used as a good biomarker for the diagnosis and prognosis of cholinesterase enzyme inhibitors insecticide poisoning.
\end{abstract}

Keywords $\beta$-glucuronidase, biomarker, cholinesterase enzyme inhibitors insecticides poisoning

\section{Introduction}

$\mathrm{O}$ rganophosphates (OPs), carbamates, and other cholinesterase inhibitors, are the most commonly used insecticides worldwide and account for more human poisonings and death annually than any other pesticide class (Watson et al., 2003).

Estimates from the WHO indicate that each year, million accidental poisonings and two million suicide attempts involving organophosphorus insecticides occur worldwide. One third of the suicides occurring globally are due to deliberate self-ingestion of pesticides (Chowdhary et al., 2014). In developing countries; exposure to insecticides constitutes one of the most common causes of poisoning. The primary reason for this is availability and easy access of pesticides together with lack of surveillance system to control its use. The mode of exposure varies including dermal, gastrointestinal and inhalational. Maximum toxic effect is through inhalation followed by gastrointestinal and dermal absorption (Kesavachandran et al., 2009).

There are more than hundred different organophosphates, which are widely used in agriculture worldwide. Organophosphates are classified as diethyl (e.g. parathion, chlorpyrifos, dichlofenthion, phorate) and dimethyl (e.g. dimethoate, 
dichlorvos, malathion) pesticides (Chowdhary et al., 2014).

The toxic effect of organophosphorus insecticides are predominantly due to inhibition of acetyl cholinesterase enzyme resulting in excessive accumulation of acetylcholine at cholinergic neuroeffector junctions (Muscarinic effects), skeletal neuromuscular junction and autonomic ganglia (Nicotinic effects) as well as central effect producing cholinergic syndrome (Eddleston and Clark, 2011).

Organophosphorus poisoning can lead to severe complications as acidosis, respiratory paralysis, acute renal failure, seizures, arrhythmias, aspiration, coma and even death. Death occurs as a result of one or more of these complications. Early diagnosis of cases of organophosphorus poisoning together with accurate evaluation and appropriate treatment are often life saving (Lee and Tai, 2001). A delay of initiation of treatments limits not only outcome, but also decreases the opportunity to use oximes (cholinesterase reactivator) (Bhattacharyya et al., 2011).

Administration of the oximes is required within $24 \mathrm{~h}$ for effective reactivation of CHE enzyme. Therefore, as soon as acute organophosphorus poisonings diagnosed, oximes should be administered before aging of the enzyme takes place. Aging is a process in which the phosphorylated enzyme is dealkylated, and reactivation with oximes becomes impossible (Peter et al., 2006).

Egasyn-B-glucuronidase complex is located at the luminal site of liver microsomal endoplasmic reticulum. When organophosphorus insecticides (OP) are incorporated into the liver microsomes, they become tightly bound to egasyn, a carboxylesterase isozyme, and subsequently, B-glucuronidase $(\beta \mathrm{G})$ is dissociated and released into blood (Johnson et al., 2000).

Hence, the aim of the present work was to assess the role of serum B-glucuronidase level as probable marker for the assessment of acute cholinesterase enzyme inhibitors insecticides poisoning.

\section{Subjects and Methods}

\section{Subjects}

The case-control study included 60 cases of acute poisoning by cholinesterase enzyme inhibitors insecticides, admitted to the Poison unit of Alexandria Main University Hospital. Another 15 age-matched healthy volunteers were included as control group. Patients selected for the study were those who were admitted within 6 hours of exposure to the poison and without receiving any prior treatment.

Exclusion criteria for selected subjects were: liver disease, severe chronic pre-existing disease, neoplasm, diabetes mellitus, or received medications.

Informed consent was obtained from all participants included in the study or from their relatives in case of comatose patients, explaining the aim and the procedure of the study. Complete confidentiality was ensured all through the study procedure. The study protocol was approved by the ethical committee of Alexandria Faculty of Medicine.

All cases were subjected to thorough history taking, full clinical examination, grading of poisoning severity score (PSS) (Eddleston et al., 2005), laboratory investigations in the form of serum cholinesterase activity level andserum B-glucuronidase level. All patients took standard treatment protocol for cholinesterase enzyme inhibitors dedicated by the patients' clinical condition.

\section{Sampling and measurement of serum $\mathrm{CHE}$ $(U / L)$ and serum $\beta$-glucuronidase $(\beta G)$ level (ng/ml)}

On admission venous blood sample was withdrawn from the patients allowing samples to clot for 2 hours at room temperature before centrifugation for 15 minutes at $1000 \mathrm{xg}$. The supernatant was collected and the assays were carried out immediately. Cholinesterase activity was determined, using the colorimetric method of Ellman (Worek et al., 2012). Serum $\beta$-glucuronidase $(\beta G)$ level was measured by enzyme-linked immunosorbent assay (Soltaninejad et al., 2010).

\section{Statistical analysis}

Data were analyzed using IBM SPSS software package version 20. Comparison between different groups regarding categorical variables was tested using Chisquare test. When more than $20 \%$ of the cells have expected count less than 5, correction for chi-square was conducted using Fisher's Exact test or Monte Carlo correction. For normally distributed data, comparison between two independent populations was done using independent t-test, while more than two populations were analyzed using F-test (ANOVA) and Post Hoc test (Scheffe). Correlations between two quantitative variables were assessed using Pearson or spearman coefficients. Agreement of serum CHE and $\beta G$ to differentiate between cases and control and outcome was used and was expressed in sensitivity, specificity, positive predictive value, negative predictive value and accuracy. Receiver operating characteristic curve (ROC) was plotted to analyze a recommended cutoff, the area under the ROC curve denotes the diagnostic performance of the test. Area more than $50 \%$ gives acceptable performance and area about $100 \%$ is the best performance for the test. Significance of the obtained results was judged at the 5\% level (Kirkpatrick and Feeney, 2013).

\section{Results}

\section{Age and sex}

The present study showed that $53.3 \%$ of cases were females $(n=32)$ and $46.7 \%$ were males $(n=28)$, with female to male sex ratio of 1.14: 1 . The youngest age encountered was one year and the oldest age was 40 years with a mean age of $17.4 \pm 10.03$ years. There was no statistical significant difference between males and females regarding their age $(\mathrm{P}>0.05)$ (Table 1). 


\section{Circumstances of poisoning}

The present study showed that the rate of suicidal poisoning was higher than accidental one. A statistically significant difference was found between both sexes regarding the circumstances of poisoning, where $\mathrm{X}^{2}=6.461, \mathrm{P}<0.011$. The majority of females (78.1\%) took the poison intentionally (suicidal), while there was a higher incidence of accidental exposure $(53.6 \%)$ than suicidal one $(46.4 \%)$ in males (Table 2$)$.

In addition, the present study showed a statistically significant association between age and circumstances of poisoning, where $\chi^{2}=39.486$, $\mathrm{P}=<0.001$. None of suicidal cases occurred at age group below 10 years, while half of suicidal cases were in age group from 20 years to less than 30 years, followed by cases in age group from 10 to less than 20 years which constituted 39.5\% (Table 3).

\section{Clinical assessment}

The studied patients were divided according to PSS into three grades, $50 \%$ of patients $(n=30)$ had score 1 (mild poisoning), 20 patients $(33.3 \%)$ had score 2 (moderate poisoning), 10 patients $(16.7 \%)$ with score 3 (severe poisoning) (Figure 1).

\section{Laboratory investigations}

The current work revealed that in control group, the levels of serum CHE ranged from $5300-12900 \mathrm{U} / \mathrm{L}$ with a mean value of $9345.33 \pm 2406.06 \mathrm{U} / \mathrm{L}$ and the levels of $\beta \mathrm{G}$ ranged from $30-1.20 \mathrm{ng} / \mathrm{ml}$, with a mean value of $0.71 \pm 0.27 \mathrm{ng} / \mathrm{ml}$. While in cases, the levels of serum CHE ranged from 600-11370 U/L with a mean value of $4306.87 \pm 3234.82 \mathrm{U} / \mathrm{L}$ and the levels of $\beta \mathrm{G}$ ranged from $3.22-10 \mathrm{ng} / \mathrm{ml}$, with a mean value of $6.17 \pm 2.03 \mathrm{ng} / \mathrm{ml}$. Serum CHE levels were significantly decreased, while Serum $\beta G$ were significantly increased in the patients compared with the controls (where, $\mathrm{z}=4.537, \mathrm{P}<0.001$ and $\mathrm{t}=20.124$, $\mathrm{P}<0.001$ respectively) (Table 4 ).

\section{ROC curve for the diagnostic performance of serum CHE and $\beta G$}

The present study showed that CHE value that was equal or less than the cutoff value of $6996 \mathrm{U} / \mathrm{L}$ was sensitive and specific in the diagnosis of OP poisoning, at sensitivity of $78.33 \%$, specificity of $86.67 \%$ and accuracy of $80 \%$. While $\beta \mathrm{G}$ value over the cutoff value of $1.2 \mathrm{ng} / \mathrm{ml}$ was sensitive and specific in the diagnosis of OP poisoning, at sensitivity of $100 \%$, specificity of $100 \%$ and accuracy of $100 \%$ (Table 5).

\section{Relation between PSS and levels of serum CHE and serum $\beta G$}

Table (6) illustrates that there was a statistically significant difference among three grades of poisoning severity regarding serum level of $\mathrm{CHE}$ cases, where $\mathrm{F}$ $=88.42$ and $\mathrm{P}<0.001$. Cases with PSS 1 (mild poisoning) had the highest levels of serum CHE, which was significantly higher than the other two grades of severity (PSS 2 and 3) using Post Hoc test (Scheffe), where $\mathrm{P}<0.001$. In addition, there was a highly significant negative correlation between level of CHE and severity of poisoning, where, $\mathrm{r}=-0.912$ and $\mathrm{P}<$ 0.001 . On the other hand, the lowest $\beta G$ values was reported in patients with mild poisoning (PSS1) which were significantly increased with increase the grade of poisoning severity, where $\mathrm{F}=207.937$ and $\mathrm{P}<$ 0.001 .There was a highly significant positive correlation between level of $\beta \mathrm{G}$ and severity of poisoning, where, $\mathrm{r}=0.913$ and $\mathrm{P}<0.001$.

On comparing the enzymatic status in mildly poisoned patients (PSS1 to that of healthy controls, the present study revealed that the levels of CHE were significantly decreased, while $\beta G$ values were significantly increased $(\mathrm{p}<0.01)$ in mildly poisoned patients. CHE levels in healthy control were 1.32times higher than mildly poisoned patients. At the same time, $\beta G$ levels were 6.22 times higher in mildly poisoned patients as compared to those in healthy controls (Table 7).

In addition, the activity of $\beta$-glucuronidase were significantly elevated $(\mathrm{p}<0.01)$ in moderately poisoned patients (PSS 2) compared to the controls, where it increased 10.18 times and 1.63times as compared to healthy controls and PSS1 patients respectively (Table 7).

The same, the activity of $\beta$-glucuronidase were significantly increased $(p<0.01)$ in severely poisoned patients (PSS3). In severely poisoned patients the activity of $\beta$-glucuronidase was 13.15 times higher as compared to controls and 1.29times higher as compared to PSS 2 patients (Table 7).

\section{ROC curve for serum CHE and $\beta G$ for detection of poison severity}

Table (8) illustrates that $\mathrm{CHE}$ value that was equal or less than the cutoff value of $1050 \mathrm{U} / \mathrm{L}$ was sensitive and specific in the diagnosis of severe OP poisoning. Moreover, CHE value over the cutoff value of 3996 $\mathrm{U} / \mathrm{L}$ was sensitive and specific in the diagnosis of mild OP poisoning, while CHE value lying in between these two cutoff values was sensitive and specific in the diagnosis of moderate cases of poisoning. All these results were at sensitivity, specificity and accuracy of $100 \%$.

ROC curve also revealed that $\beta$ Gvalue over cutoff value of $8.65 \mathrm{ng} / \mathrm{ml}$ was sensitive and specific in the diagnosis of severe OP poisoning. Moreover, $\beta \mathrm{G}$ value that was equal or less than the cutoff value of 5.7 $\mathrm{ng} / \mathrm{ml}$ was sensitive and specific in the diagnosis of mild OP poisoning, while $\beta \mathrm{G}$ value lying in between these two cutoff values was sensitive and specific in the diagnosis of moderate cases of poisoning. Also, all these results were at sensitivity, specificity and accuracy of $100 \%$.

\section{Duration of hospitalization and outcome}

Regarding the length of stay of patients in hospital in the current work, it ranged from one to 18 days, with a mean of $4.38 \pm 4.03$ days. Complete recovery without sequelae occurred in $95 \%$ of cases $(n=57)$, while death occurred in $5 \%$ of cases $(n=3), 2$ on day 15 and the third one on day 18 after poisoning. The cause of death appeared to be cardio-respiratory failure.

Table (9) shows that there was a statistically significant association between length of hospitalization and grades of poison severity, 
where $^{\mathrm{KW}} \boldsymbol{\chi}^{2}=44.868$ and $\mathrm{P}<0.001$.The duration of hospitalization was significantly increased in moderate cases than mild ones and in severe cases than moderate and mild ones using Mann Whitney test.

Table (10) illustrates the significant negative correlation between level of serum $\mathrm{CHE}$ and duration of hospitalization, where $\mathrm{r}=-0.799$ and $\mathrm{P}<0.001$. On the other hand, it shows the significant positive correlation between serum level of $\beta \mathrm{G}$ and length of hospital stay.

Table (11) illustrates that there was a statistically significant association between outcome and grades of poison severity, where ${ }^{\mathrm{FE}} \chi^{2}=15.789$ and $\mathrm{P}=0.003$. The three dead cases were having the PSS 3 (severe grade), there was a statistically significant difference between PSS 3 and both PSS1 and PSS 2 using Chi square test, where $\mathrm{p} \leq 0.05$.

\section{ROC curve for serum CHE and $\beta$ G for prediction of outcome}

The present study showed that CHE value that was equal or less than the cutoff value of $849 \mathrm{U} / \mathrm{L}$ was sensitive and specific in the prediction of outcome of OP poisoning, at sensitivity of $100 \%$, specificity of $91.23 \%$ and accuracy of $91.67 \%$. While $\beta G$ value over the cutoff value of $8.9 \mathrm{ng} / \mathrm{ml}$ was sensitive and specific in the prediction of outcome of OP poisoning, at sensitivity of $100 \%$, specificity of $91.23 \%$ and accuracy of $91.67 \%$ (Table 12).

\section{Correlation between levels of CHE and $\beta \mathrm{G}$ in each studied group}

Table 13 shows that there was a significant inverse correlation between levels of $\mathrm{CHE}$ and $\beta \mathrm{G}$ whether in control group or in cases, where $r=-0.639, \mathrm{P}=0.01$ and $r=-0.915, \mathrm{p}<0.001$ respectively).

Table (1): Percentage and relation between sex and age in studied cases $(n=60)$

\begin{tabular}{|c|c|c|c|c|c|c|}
\hline & \multicolumn{2}{|c|}{ Male $(n=28)$} & \multicolumn{2}{|c|}{ Female $(n=32)$} & \multicolumn{2}{|c|}{ Total $(n=60)$} \\
\hline & No. & $\%$ & No. & $\%$ & No. & $\%$ \\
\hline \multicolumn{7}{|l|}{ Age } \\
\hline $0-<10$ & 8 & $28.6 \%$ & 7 & $21.9 \%$ & 15 & $25 \%$ \\
\hline $10-<20$ & 5 & $17.9 \%$ & 11 & $34.4 \%$ & 16 & $26.7 \%$ \\
\hline $20-<30$ & 10 & $35.7 \%$ & 12 & $37.5 \%$ & 22 & $36.7 \%$ \\
\hline $30-40$ & 5 & $17.9 \%$ & 2 & $6.3 \%$ & 7 & $11.7 \%$ \\
\hline$\chi^{2}$ & \multicolumn{4}{|c|}{3.445} & & \\
\hline${ }^{M C} \mathbf{P}$-value & \multicolumn{4}{|c|}{$0.330(\mathrm{NS})$} & \multirow{2}{*}{\multicolumn{2}{|c|}{$1.0-40.0$}} \\
\hline Min. - Max. & \multicolumn{2}{|c|}{$1.0-40.0$} & \multicolumn{2}{|c|}{$2.0-31.0$} & & \\
\hline Mean \pm SD. & \multicolumn{2}{|c|}{$18.61 \pm 11.56$} & \multicolumn{2}{|c|}{$16.35 \pm 8.52$} & \multicolumn{2}{|c|}{$17.4 \pm 10.03$} \\
\hline Median & & 0.0 & & 3.0 & \multicolumn{2}{|c|}{19.0} \\
\hline $\mathbf{Z}$ & \multicolumn{4}{|c|}{0.823} & & \\
\hline P-value & \multicolumn{4}{|c|}{$0.410(\mathrm{NS})$} & & \\
\hline
\end{tabular}

$\chi^{2}:$ for Chi square test, MC: Monte Carlo test; Z: Z for Mann

Whitney test; NS: Non significant

Table (2): Statistical analysis $\left(X^{2}\right)$ between sex and circumstances of poisoning in studied cases $(n=60)$

\begin{tabular}{|c|c|c|c|c|c|c|}
\hline & \multicolumn{2}{|c|}{$\begin{array}{c}\text { Male } \\
(n=28)\end{array}$} & \multicolumn{2}{|c|}{$\begin{array}{c}\text { Female } \\
(n=32)\end{array}$} & \multicolumn{2}{|c|}{$\begin{array}{c}\text { Total } \\
(n=60)\end{array}$} \\
\hline & No. & $\%$ & No. & $\%$ & No. & $\%$ \\
\hline \multicolumn{7}{|l|}{ Circumstances of poisoning } \\
\hline Accidental & 15 & $53.6 \%$ & 7 & $21.9 \%$ & 22 & $36.7 \%$ \\
\hline Suicidal & 13 & $46.4 \%$ & 25 & $78.1 \%$ & 38 & $63.3 \%$ \\
\hline$\chi^{2}$ & \multicolumn{4}{|c|}{$6.461^{*}$} & & \\
\hline${ }^{M} C_{p}$ & \multicolumn{4}{|c|}{$0.011^{*}$} & & \\
\hline
\end{tabular}

ఒ2: value for Chi square; MC: Monte Carlo test; *: Statistically significant at $p \leq 0.05$ 
Table (3): Statistical analysis $\left(\mathrm{X}^{2}\right)$ between age and circumstances of exposure in cases group

\begin{tabular}{|c|c|c|c|c|c|c|}
\hline & \multicolumn{4}{|c|}{ Circumstances of exposure } & \multirow{2}{*}{\multicolumn{2}{|c|}{$\begin{array}{c}\text { Total } \\
(n=60)\end{array}$}} \\
\hline & \multicolumn{2}{|c|}{ Accidental $(n=22)$} & \multicolumn{2}{|c|}{ Suicidal $(n=38)$} & & \\
\hline & No. & $\%$ & No. & $\%$ & No. & $\%$ \\
\hline \multicolumn{7}{|l|}{ Age } \\
\hline $0-<10$ & 15 & $68.2 \%$ & 0 & $0.0 \%$ & 15 & $25 \%$ \\
\hline $10-<20$ & 1 & $4.5 \%$ & 15 & $39.5 \%$ & 16 & $26.7 \%$ \\
\hline $20-<30$ & 3 & $13.6 \%$ & 19 & $50 \%$ & 22 & $36.7 \%$ \\
\hline $30-40$ & 3 & $13.6 \%$ & 4 & $10.5 \%$ & 7 & $11.7 \%$ \\
\hline$\chi^{2}$ & \multicolumn{4}{|c|}{$39.486^{*}$} & & \\
\hline${ }^{M} \mathbf{M}_{\mathbf{p}}$ & \multicolumn{4}{|c|}{$<0.001^{*}$} & & \\
\hline
\end{tabular}

ఒ2: value for Chi square, MC: Monte Carlo test; *: Statistically significant at $p \leq 0.05$

Table (4): Statistical analysis (t-test) for comparison between cases and control according to serum CHE, serum BG

\begin{tabular}{|c|c|c|c|c|}
\hline & Cases $(n=60)$ & Control $(n=15)$ & Test of sig. & $\mathbf{p}$ \\
\hline \multicolumn{5}{|c|}{ Serum CHE(U/L) } \\
\hline Min. - Max. & $600-11370$ & $5300-12900$ & \multirow[t]{3}{*}{$\mathrm{t}=4.537^{*}$} & \multirow[t]{3}{*}{$<0.001^{*}$} \\
\hline Mean \pm SD. & $4306.87 \pm 3234.82$ & $9345.33 \pm 2406.06$ & & \\
\hline Median & 3996.0 & 9200.0 & & \\
\hline \multicolumn{5}{|l|}{ Serum $\beta G(\mathrm{ng} / \mathrm{ml})$} \\
\hline Min. - Max. & $3.22-10$ & $0.30-1.20$ & \multirow[t]{3}{*}{$\mathrm{t}=20.124^{*}$} & \multirow[t]{3}{*}{$<0.001^{*}$} \\
\hline Mean \pm SD. & $6.17 \pm 2.03$ & $0.71 \pm 0.27$ & & \\
\hline Median & 5.75 & 0.70 & & \\
\hline
\end{tabular}

t: Student t-test; *: Statistically significant at $p \leq 0.05$

Table (5): Agreement (sensitivity, specificity and accuracy) for serum CHE and $\beta$ Gwith both studied groups (for the diagnostic performance of serum $\mathrm{CHE}$ and $\beta \mathrm{G}$ with studied groups)

\begin{tabular}{|c|l|c|c|c|c|c|}
\hline & & Sensitivity & Specificity & PPV & NPV & Accuracy \\
\hline Serum CHE (U/L) & $>6996$ & 78.33 & 86.67 & 95.92 & 50.0 & 80.0 \\
\cline { 2 - 7 } & $\leq 6996$ & & & & & \\
\hline Serum $\beta \mathrm{G}(\mathrm{ng} / \mathrm{ml})$ & $\leq 1.2$ & 100.0 & 100.0 & 100.0 & 100.0 & 100.0 \\
\cline { 2 - 7 } & $>1.2$ & & & & & \\
\hline
\end{tabular}

Table (6): Correlation between PSS and levels of serum CHE and serum $\beta G$

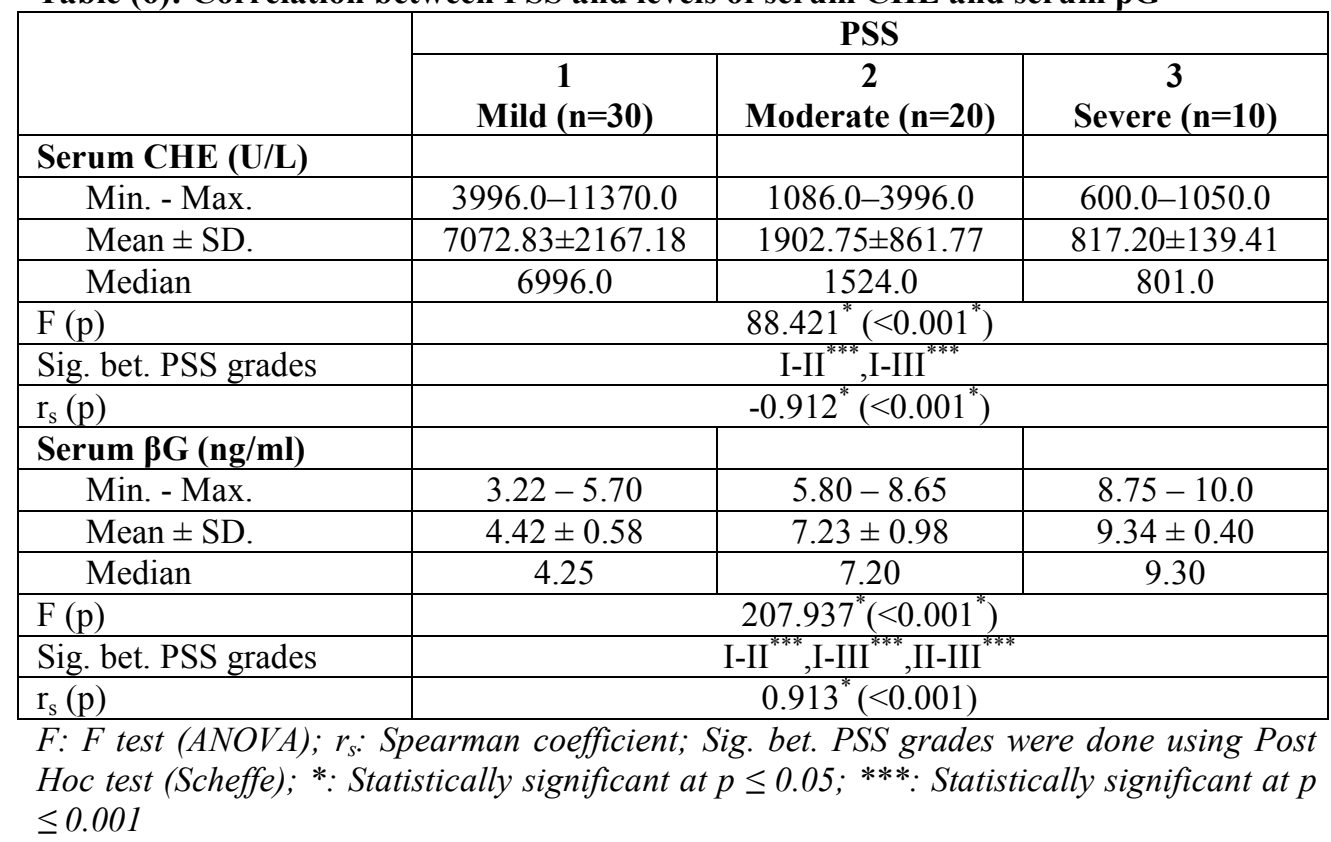


Table (7): Levels of serum CHE and serum $\beta G$ in controls and 3 grades of poisoning

\begin{tabular}{|c|c|c|c|c|}
\hline \multirow[b]{2}{*}{ Parameters } & \multirow[b]{2}{*}{ Control $(n=15)$} & \multicolumn{3}{|c|}{ PSS } \\
\hline & & $\begin{array}{c}1 \\
\text { Mild }(n=30)\end{array}$ & $\begin{array}{c}2 \\
\text { Moderate }(n=20)\end{array}$ & $\begin{array}{c}3 \\
\text { Severe }(n=10)\end{array}$ \\
\hline CHE & $9345.33 \pm 2406.06$ & $7072.83 \pm 2167.18$ & $1902.75 \pm 861.77$ & $817.20 \pm 139.41$ \\
\hline $\mathrm{F}$ & \multicolumn{4}{|c|}{$78.862^{*}$} \\
\hline $\begin{array}{l}\text { P-value compared to } \\
\text { control }\end{array}$ & - & $<0.001^{*}$ & $<0.001^{*}$ & $<0.001^{*}$ \\
\hline $\mathrm{r}_{\mathrm{s}}(\mathrm{p})$ & \multicolumn{4}{|c|}{$-0.879^{*}(<0.001)$} \\
\hline B- gluc & $0.71 \pm 0.27$ & $4.42 \pm 0.58$ & $7.23 \pm 0.98$ & $9.34 \pm 0.40$ \\
\hline $\mathrm{F}$ & \multicolumn{4}{|c|}{$445.664^{*}$} \\
\hline $\begin{array}{l}\text { P-value compared to } \\
\text { control }\end{array}$ & - & $<0.001^{*}$ & $<0.001^{*}$ & $<0.001^{*}$ \\
\hline$r_{s}(p)$ & \multicolumn{4}{|c|}{$0.952^{*}(<0.001)$} \\
\hline
\end{tabular}

F: F test (ANOVA); $r_{s}$ : Spearman coefficient; *: Statistically significant at $p \leq 0.001$

Table (8): Agreement (sensitivity, specificity and accuracy) for serum CHE and $\beta$ G with PSS

\begin{tabular}{|c|c|c|c|c|c|c|c|c|}
\hline Cutoff value & Mild & Moderate & Severe & Sensitivity & Specificity & PPV & NPV & Accuracy \\
\hline Serum CHE (U/L) & $>3996$ & $>1050-3996$ & $\leq 1050$ & 100.0 & 100.0 & 100.0 & 100.0 & 100.0 \\
\hline Serum $\beta \mathrm{G}(\mathrm{ng} / \mathrm{ml})$ & $\leq 5.7$ & $>5.7-8.65$ & $>8.65$ & 100.0 & 100.0 & 100.0 & 100.0 & 100.0 \\
\hline
\end{tabular}

Table (9): Relation between PSS and duration of hospitalization

\begin{tabular}{|c|c|c|c|c|}
\hline & \multicolumn{3}{|c|}{ PSS } & \multirow[b]{2}{*}{ Total $(n=60)$} \\
\hline & $\begin{array}{c}1 \\
\text { Mild }(n=30)\end{array}$ & $\begin{array}{c}2 \\
\text { Moderate }(n=20)\end{array}$ & $\begin{array}{c}3 \\
\text { Severe }(n=10)\end{array}$ & \\
\hline \multicolumn{5}{|c|}{ Duration of hospitalization } \\
\hline Min. - Max. & $1.0-7.0$ & $3.0-8.0$ & $3.0-18.0$ & $1.0-18.0$ \\
\hline Mean \pm SD. & $1.63 \pm 1.13$ & $5.25 \pm 1.74$ & $10.90 \pm 4.70$ & $4.38 \pm 4.03$ \\
\hline Median & 1.0 & 5.0 & 11.50 & 3.0 \\
\hline${ }^{\mathrm{KW}} \chi^{2}(\mathrm{p})$ & \multicolumn{3}{|c|}{$44.868^{*}\left(<0.001^{*}\right)$} & \\
\hline Sig. bet. PSS grades & \multicolumn{3}{|c|}{ I-II $^{* * *}$, I-III $^{* * *}$, II-III ${ }^{* * *}$} & \\
\hline
\end{tabular}

${ }^{K W} \chi^{2}$ : Chi square test value for Kruskal Wallis test; Sig. bet. PSS grades was done using Mann Whitney test; *: Statistically significant at $p \leq 0.05$; **: Statistically significant at $p \leq 0.01$; ***: Statistically significant at $p \leq 0.001$

Table (10): Correlation between length of hospital stay with BG and CHE in cases group

\begin{tabular}{|l|c|c|}
\hline & \multicolumn{2}{|c|}{ Length of hospital stay } \\
\hline & $\mathbf{r}_{\mathbf{s}}$ & $\mathbf{p}$ \\
\hline Serum CHE & $-0.779^{*}$ & $<0.001$ \\
\hline Serum BG & $0.788^{*}$ & $<0.001$ \\
\hline
\end{tabular}

$r_{s}$ : Spearman coefficient; *: Statistically

significant at $p \leq 0.05$

Table (11): Relation between PSS and outcome

\begin{tabular}{|c|c|c|c|c|c|c|c|c|}
\hline & \multicolumn{6}{|c|}{ PSS } & \multirow{2}{*}{\multicolumn{2}{|c|}{ Total $(n=60)$}} \\
\hline & \multicolumn{2}{|c|}{$\begin{array}{l}1 \\
\text { Mild }(n=30)\end{array}$} & \multicolumn{2}{|c|}{$\begin{array}{c}2 \\
\text { Moderate }(n=20)\end{array}$} & \multicolumn{2}{|c|}{$\begin{array}{c}3 \\
\text { Severe }(n=10)\end{array}$} & & \\
\hline & No. & $\%$ & No. & $\%$ & No. & $\%$ & No. & $\%$ \\
\hline \multicolumn{9}{|l|}{ Outcome } \\
\hline Recovery & 30 & 100.0 & 20 & 100.0 & 7 & 70.0 & 57 & 95.0 \\
\hline Death & 0 & 0.0 & 0 & 0.0 & 3 & 30.0 & 3 & 5.0 \\
\hline$\chi^{2}\left({ }^{\mathrm{FE}} \mathrm{p}\right)$ & \multicolumn{6}{|c|}{$15.789^{*}\left(0.003^{*}\right)$} & & \\
\hline Sig. bet. PSS grades & \multicolumn{6}{|c|}{ I-III $^{*}, \mathrm{II}-\mathrm{III}^{*}$} & & \\
\hline
\end{tabular}

$\chi^{2}$ : value for Chi square; FE: Fisher Exact test; Sig. bet. PSS grades were done using Chi square; *: Statistically significant at $p \leq 0.05$; ***: Statistically significant at $p \leq 0.001$ 
Table (12): Agreement (sensitivity, specificity and accuracy) for serum CHE and $\beta$ Gwith patients' outcome.

\begin{tabular}{|l|l|c|c|c|c|c|c|c|}
\hline & & Recovery & Death & Sensitivity & Specificity & PPV & NPV & Accuracy \\
\hline \multirow{2}{*}{$\begin{array}{l}\text { Serum CHE } \\
(\mathrm{U} / \mathrm{L})\end{array}$} & $>849$ & 52 & 0 & 100.0 & 91.23 & 37.50 & 100.0 & 91.67 \\
\cline { 2 - 8 } & $\leq 849$ & 5 & 3 & & & & & \\
\cline { 1 - 5 } $\begin{array}{l}\text { Serum } \beta \mathrm{G} \\
(\mathrm{ng} / \mathrm{ml})\end{array}$ & $\leq 8.9$ & 52 & 0 & 100.0 & 91.23 & 37.50 & 100.0 & 91.67 \\
\cline { 2 - 7 } & $>8.9$ & 5 & 3 & & & & \\
\hline
\end{tabular}

Table (13): Correlation between levels of CHE and $\beta G$ in each studied group

\begin{tabular}{|l|c|c|}
\hline \multirow{2}{*}{} & \multicolumn{2}{|c|}{ Levels of CHE versus $\boldsymbol{\beta G}$} \\
\cline { 2 - 3 } & $\mathbf{r}$ & $\mathbf{p}$ \\
\hline Cases group & $-0.915^{*}$ & $<0.001$ \\
\hline Control group & $-0.639^{*}$ & 0.010 \\
\hline
\end{tabular}

$r$ : Pearson coefficient; *: Statistically significant at $p \leq 0.05$

Table (14): Accuracy, sensitivity and specificity for diagnostic and prognostic performance of both studied biomarkers $(\mathbf{n}=60)$.

\begin{tabular}{|l|l|c|c|c|}
\hline Parameters & \multicolumn{1}{|c|}{ Cutoff point } & Overall accuracy $\%$ & Sensitivity & Specificity \\
\hline Serum CHE (U/L) & Cases $\leq 6996<$ Control & $80 \%$ & $78.33 \%$ & $86.67 \%$ \\
\hline Serum $\beta \mathrm{G}(\mathrm{ng} / \mathrm{ml})$ & Control $\leq 1.2<$ Cases & $100 \%$ & $100 \%$ & $100 \%$ \\
\hline Serum CHE (U/L) & $\begin{array}{l}\text { Mild }>3996 \\
\text { Moderate }>1050-3996 \\
\text { Severe } \leq 1050\end{array}$ & $100 \%$ & $100 \%$ & $100 \%$ \\
\hline Serum $\beta \mathrm{G}(\mathrm{ng} / \mathrm{ml})$ & $\begin{array}{l}\text { Mild } \leq 5.7 \\
\text { Moderate }>5.7-8.65 \\
\text { Severe }>8.65\end{array}$ & $100 \%$ & $100 \%$ & $100 \%$ \\
\hline Serum CHE (U/L) & Death $\leq 849<$ Recovery & $91.67 \%$ & $100 \%$ & $91.23 \%$ \\
\hline Serum $\beta \mathrm{G}(\mathrm{ng} / \mathrm{ml})$ & Recovery $\leq 8.9<$ Death & $91.67 \%$ & $100 \%$ & $91.23 \%$ \\
\hline
\end{tabular}

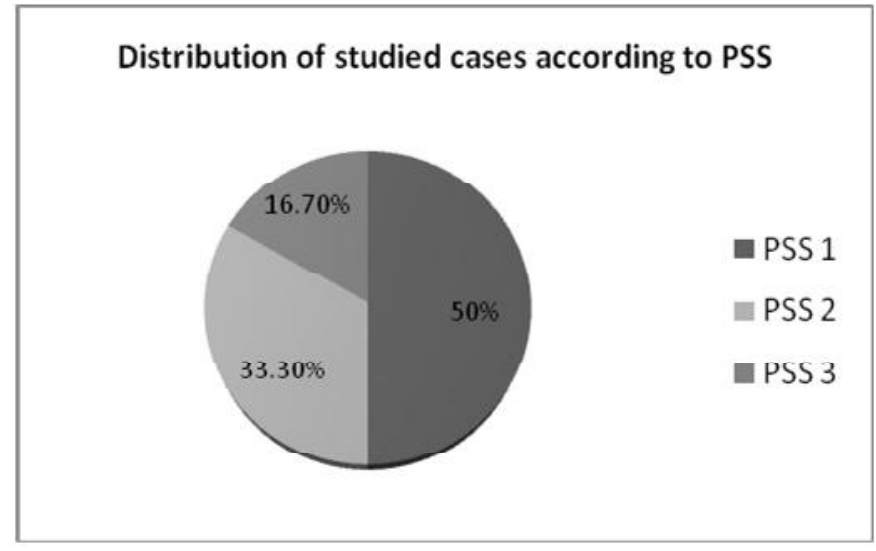

Figure (1): Distribution of studied cases according to poison severity score.

\section{Discussion}

Organophosphate (OP) poisoning is an important clinical problem in the developing world especially in rural regions, and severe acute OP poisoning is a medical emergency (Eddleston et al., 2008). The mortality rate for OP poisoning is high, with fatality often related to a delay in diagnosis or improper management (Sungur and Guven, 2001).

The present study showed that $53.3 \%$ of cases were females $(n=32)$ and $46.7 \%$ were males $(n=28)$. The same finding was reported by Akdur et al., (2010). The mean age of patients was $17.4 \pm 10.03$ years which is consistent with Khan and Reza, (1998) who reported that most OP patients were under the age of 30 years with predominance of females.

The present study showed that the rate of suicidal poisoning was higher than accidental one, this may be explained by cheap price and uncontrolled sale of insecticide over the counter in developing countries. A statistically significant difference between both sexes regarding the circumstances of poisoning was found, where the majority of females $(78.1 \%)$ took the poison intentionally (suicidal). women tend to use less lethal means of suicide which carry a higher chance of survival and they more commonly express an appeal 
for help by conducting the attempt in a manner that favors discovery and rescue.(Hanna et al, 2011)Half of suicidal cases were in age group from 20 years to less than 30 years and $39.5 \%$ of suicidal cases were in age group from 10 to less than 20 years. This may be attributed to the emotional instability and problems facing teenagers and youth.

In modern clinical medicine, the search for specific sensitive biomarkers for syndromes is increasing. These biomarkers are mainly focusing to confirm diagnosis, predict outcome or to add value in the follow-up. In clinical practice, diagnosis of an acute organophosphorus (OP) poisoning depends mainly on history of exposure, physical manifestations, clinical suspicion, and laboratory support. Until now, measuring the acetyl cholinesterase activity in the red blood cells was considered to be the standard to evaluate the biochemical effects and severity following an acute and chronic OP overdose (Lockridge and Schopfer, 2006). However, this technique needs expertise, and in many clinical laboratories, pseudocholinesterase activity is measured because of its simplicity and relative accuracy.

Plasma CHE is subject to variations induced by hereditary deficiency of the enzyme, liver dysfunction, malnutrition, and drugs such as cocaine and opioids and thus less specific. Additionally, dayto-day variation in the activity of this enzyme in healthy individuals may be as high as 20\% (Eddleston and Clark, 2011). Furthermore, intra-individual variation of blood cholinesterase activity has been reported as $6.3 \%$ for men and $6.7 \%$ for women respectively (Chowdhary et al., 2014). Therefore, a search for a more sensitive and specific biomarker for such a potentially severe poisoning is of health care benefit especially that OP patients admitted in good condition can be rapidly deteriorated requiring intubation and mechanical ventilation (Sungurtekin et al., 2006).

There are emerging options for new cheaper and/or easily quantifiable biochemical markers in relation to OP poisoning like creatine phosphokinase (CPK), lactate dehydrogenase (LDH), serum immunoglobulins (IgG, IgA), circulating complements (C3, C4), etc. But the main disadvantage with these markers is their non-specificity. Moreover, immunoglobulin assays, apart from being costly and difficult to perform in most laboratories, are often unreliable (Bhattacharyya et al., 2011). Yarden et al., (2013) suggested that S100B protein may be a useful marker in assessment of clinical severity and predicting mortality of OP poisoning.

In the present study, there was a statistically significant difference between cases and control regarding both $\mathrm{CHE}$ and $\beta \mathrm{G}$ levels in serum.

Cholinesterase activity was decreased to approximately $50 \%$ of the control level, while plasma BG was significantly increased to be approximately 8.5 times the control level. This indicates that increase of plasma BG activity is much more susceptible than cholinesterase inhibition to insecticides.

Satoh et al., (1999) also stated that increase of the plasma BG level after OP administration is much more sensitive biomarker than cholinesterase inhibition to acute intoxication of OPs and carbamates as the change occurred in BG level after exposure was much higher than that occurred in CHE level (150\% versus $50 \%)$.

CHE value that was equal or less than the cutoff value of $6996 \mathrm{U} / \mathrm{L}$ was sensitive and specific in the diagnosis of OP poisoning with accuracy of $80 \%$. While $\beta G$ value over the cutoff value of $1.2 \mathrm{ng} / \mathrm{ml}$ was sensitive and specific in the diagnosis of OP poisoning with accuracy of $100 \%$. Sensitivity means (true positive) which is more important and has higher value than the specificity which is (true negative). These data suggest that $\beta$ Gwas more helpful in diagnosis of OP poisoning than $\mathrm{CHE}$.

Fujikawa et al., (2005) reported that $\beta$ glucuronidase was a much more sensitive biomarkerfor acute OP exposure than acetyl cholinesterase inhibition. Where, a single administration of EPN (Oethyl O-p-nitrophenyl phenyl phosphonothioate) and chlorpyrifos increased plasma $\beta G$ activity in approximately 100-fold the control level (peak time of increase BG levels was between 2-5 hours after OP treatment). However, these reported findings were produced using a rat model.

Serum CHE values were significantly decreased with increase the grade of poisoning severity. A highly significant negative correlation was detected between level of CHE and severity of poisoning in the present study. This is in agreement with Kandalaft et al., (1991).

In the current study, $\beta G$ values were significantly increased with increase the grade of poisoning severity. A highly significant positive correlation was detected between level of $\beta G$ and severity of poisoning. Similarly, Kale, (2013) found a proportional increase in $(\beta G)$ activity with severity of organophosphorus poisoning which will be helpful in the diagnosis and prognosis of organophosphorus poisoning.

On contrary, Sabbe et al., (2008) reported that on taking serial samples for measurement of both serum $\mathrm{CHE}$ and $\beta \mathrm{G}$, the serum CHE activity supported the clinical findings and helped to decide when the patient could be weaned of the ventilator. While, $\beta$ glucuronidase activity surprisingly decreased with time, but within the normal range.

Similarly, BG activity in experimental animals was found to increase rapidly to a maximum level about $1 \mathrm{~h}$ after exposure and returned to a baseline level within $24 \mathrm{~h}$ (Kikuchi et al., 1981). In contrast, for an OP-induced decrease in serum CHE activity, it occurred immediately after high dose OP 
exposure and took more than 20-30 days to recover to the base level (O’Malley, 2007). These findings raised the possibility that an OP-induced change in BG activity might reflect more recent $\mathrm{OP}$ exposure compared with blood CHE activity. This advantage of BG makes it more helpful in determining the efficacy of oxime administration.

On comparing the enzymatic status in mildly poisoned patients (PSS1 to that of healthy controls, the present study revealed that the levels of CHE were significantly decreased, while $\beta G$ values were significantly increased $(\mathrm{p}<0.01)$ in mildly poisoned patients. CHE levels in healthy control were 1.32times higher than mildly poisoned patients. On the other hand, $\beta G$ levels were 6.22times higher in mildly poisoned patients as compared to those in healthy controls. So, the present work revealed that $(\beta \mathrm{G})$ activity was helpful in diagnosis of low dose (mild) poisoning.

Ueyama et al., (2010) concluded that plasma $\beta G$ activity is more sensitive biomarker as well as urinary OP metabolites than serum CHE for low-level exposure in humans. On contrary, Soltaninejad et al., (2007) observed a significant increase in blood BG activity only in patients severely intoxicated by OP exposure compared to that in controls and this may be explained by their small sample size (22 patients).

The data obtained from ROC curve analysis suggest that both serum $\mathrm{CHE}$ and $\beta$ Gwere equal in predicting the severity of OP poisoning (table 8). Yarden et al., (2013) stated that serum CHE level is related to the clinical severity but not with mortality. In contrast, other previous studied reported that low serum CHE support the diagnosis of OP poisoning but are not significantly related to the severity of poisoning (Aygun et al., 2002, Yun et al., 2012). These different results may be associated with the different grading systems used in those studies.

There was a significant increase in length of hospital stay of patients with increased poisoning severity in the current study. This reflects the socioeconomic aspect associated with organophosphorus intoxication especially in severe cases resulting in increased cost of treatment and days of absence from work.

The present study showed a significant negative correlation between level of serum CHE and duration of hospitalization. On the other hand, it showed a significant positive correlation between serum level of $\beta G$ and length of hospital stay.

A significant mortality prediction was detected with increased severity of poisoning in the studied patients. All mortality cases had the highest grade of severity (PSS 3). This is consistent with results reported by Tsao et al., (1990) and Cunha et al., (1995).

The present study showed that CHE value that was equal or less than the cutoff value of $849 \mathrm{U} / \mathrm{L}$ was sensitive and specific in the prediction of outcome of OP poisoning with accuracy of $91.67 \%$. While $\beta G$ value over the cutoff value of $8.9 \mathrm{ng} / \mathrm{ml}$ was sensitive and specific in the prediction of outcome of OP poisoning with accuracy of $91.67 \%$. These data suggest that both $\mathrm{CHE}$ and $\beta \mathrm{Gwere}$ equal in predicting the outcome of OP poisoning.

In addition, the current work revealed that there was an inverse correlation between levels of CHE and $\beta \mathrm{G}$ whether in control group or in cases.

Consequently, the increase in plasma $\beta G$ activity could be a good biomarker of cholinesterase enzyme inhibitor insecticides exposure even in mild cases of poisoning.

\section{Recommendation}

The present work recommends for making researches which include dose-response relationship between OP exposure and BG activity in the human body, due in part to the difficulty in determining the exact OP exposure level and elapsed time after the exposure, plotting time-activity curve of BG activity after OP exposure in the human body.

\section{References}

Akdur O, Durukan P, Ozkan S, et al. (2010): Poisoning severity score, Glasgow coma scale, corrected QT interval in acute organophosphate poisoning. Hum Exp Toxicol. 32 (10): 1081-8.

Aygun D, Doganay Z, Altintop L, et al. (2002): Serum acetylcholinesterase and prognosis of acute organophosphate poisoning. J ToxicolClin Toxicol.40: 903-10.

Bhattacharyya K, Phaujdar S, Sarkar R, et al. (2011): Serum creatine phosphokinase: A probable marker of severity in organophosphorus poisoning. Toxicol Int. 18(2): 117-23.

Chowdhary S, Bhattacharyya R and Banerjee D (2014): Acute organophosphorus poisoning. ClinicaChimicaActa. 431: 66-76.

Cunha J, Póvoa P, Mourão L, et al. (1995): Severe poisoning by organophosphate compounds. An analysis of mortality and of the value of serum cholinesterase in monitoring the clinical course. Acta Med Port.8(9):469-75.

Eddleston M and Clark RF (2011): Insecticides: organic phosphorus compounds and carbamates. In: Goldfrank's toxicologic emergencies, Nelson LS, Lewin NA and Howland MA (eds), 9th ed ,McGraw-HillNew York, NY, pp. 1450-6.

Eddleston M, Buckley NA, Eyer P, et al., (2008): Management of acute organophosphorus pesticidepoisoning. Lancet 371: 597-607.

Eddleston M, Eyer P, WorekF, et al., (2005): Differences between organopphosphorus 
insecticides in human self poisoning: a prospective cohort study. Lancet 366: 1452- 9.

Fujikawa Y, Satoh T, Suganuma A, et al.(2005): Extremely sensitive biomarker of acute organophosphorus insecticide exposure. Human and Experimental Toxicology. 24(6): 333-6.

Hanna MM, El-Shereef E, Azza H. et al. (2011): Study of pattern and outcome of suicidal methods usedin Benghazi City - Libya. Egyptian Journal of Forensic Sciences. 1:124-32.

Johnson MK, Jacobsen D and Meredith TJ (2000): Evaluation of antidotes for poisoning by organophosphorus pesticides. Emerg Med. 12: $22-37$.

Kale B(2013): $\beta$ - Glucuronidase as a new potent biomarker in the diagnosis and prognosis of organophosphorus toxicity. International Journal of Biological Research. 1 (1): 5-9.

Kandalaft K, S Liu S, Manivel C (1991): Organophosphate increases the sensitivity of human exocrine pancreas to acetylcholine. Pancreas. 6:398-403.

Kesavachandran CN, Fareed M, Pathak MK, et al. (2009): Adverse health effects of pesticides in agrarian populations of developing countries. Rev Environ ContamToxicol.200:33-52.

Khan MM and Reza H (1998): Gender differences in nonfatal suicidal behavior in Pakistan: significance of sociocultural factors. Suicide Life Threat Behav. 28(1):62-8.

Kikuchi H, Suzuki Y and Hashimoto Y (1981): Increase of beta-glucuronidase activity in the serum of rats administered organophosphate and carbamate insecticides. J. Toxicol. Sci.6: 27-35.

Kirkpatrick LA and Feeney BC (2013): A simple guide to IBM SPSS statistics for version 20. Student ed., Wadsworth, Cengage Learning, Belmont, Calif.

Lee P and Tai Dy (2001): Clinical features of patients with acute organophosphorus poisoning requiring intensive care. Intensive Care Med. 27(4):694-9.

Lockridge O andSchopfer LM (2006): Biomarkers of organophosphate exposure. In: Toxicology of Organophosphate and Carbamate Compounds Gupta, RC (ed), Academic Press/Elsevier , Amsterdam, p. 703-11.

O’Malley MA (2007): Pesticide. In: Current Occupational and Environmental Medicine LaDou, J. (Ed.), 4th ed. McGraw-Hill, New York, p. 544.

Peter JV, Moran JL, Graham P (2006): Oxime therapy and outcomes in human organophosphate poisoning: an evaluation using meta-analytic techniques. Crit Care Med. 34:502-10.
Sabbe MB1, Desruelles D, Lissens W (2008): Is betaglucuronidase a clinical useful biomarker for an acute organophosphorus poisoning? Hum Exp Toxicol. 27(5): 431-3.

Satoh T, Suzuki S, Kawai N, et al.(1999): Toxicological significance in the cleavage of esterase-beta-glucuronidase complex in liver microsomes by organophosphorus compounds. Chem-Biol Interact.119-120: 471-8.

Soltaninejad K, Shadnia S, Afkhami-Taghipour M, et al. (2010): Laboratory of Forensic Toxicology, Legal Medicine Organization, Tehran, Iran. Toxicol Lett. 193(1):115-9.

Soltaninejad K, Shadnia S, Afkhami-Taghipour M, et al.(2007): Blood beta-glucuronidase as a suitable biomarker at acute exposure of severe organophosphorus poisoning in human. Human and Experimental Toxicology 26: 963-6.

Sungur M and Guven M (2001): Intensive care management of organophosphate insecticide poisoning. Crit Care 5: 211-5.

Sungurtekin H, Gurses E and Balci C (2006): Evaluation of several clinical scoring tools in organophosphate poisoned patients. Clin Toxicol (Phila). 44:121-6.

Tsoa ICY, Juang YC, Lan RS, et al. (1990): Respiratory failure of acute organophosphate and carbamate poisoning. Chest 98:631-36.

Ueyamaa J, Satoh T, Kondo T, et al. (2010): $\beta$ Glucuronidase activity is a sensitive biomarker to assess low-level organophosphorus insecticide exposure. Toxicology Letters 193: 115-9.

Watson WA, Litovitz TL and Rodgers CG (2003):2002 annual report of the American Association of Poison Control Centers Toxic Exposure Surveillance System. Am J Emerg Med. 21(5): 353-421.

Worek F, Eyer P, and Thiermann H (2012): Determination of acetyl cholinesterase activity by the Ellman assay: a versatile tool for in vitro research on medical counter measures against organophosphate poisoning. Drug Test Anal.4:282-91.

Yardan T, Baydin A, Acar E, et al.(2013): The role of serum cholinesterase activity and S100B protein in the evaluation of organophosphate poisoning. Human and Experimental Toxicology. 32(10) 1081-8.

Yun HW, Lee DH, Lee JH, et al.(2012): Serial serum cholinesterase activities as a prognostic factor in organophosphate poisoned patients. Hong Kong J Emerg Med. 19: 92-7. 


\section{الملخص العربى}

\section{دراسةعلي إنزيم بيتا جلكيورينيداز كعلامة حيوية محتملة في حالات التسمم الحاد بالمبيدات المثبطةلإنزيم} كولينيستيريز

\section{منال حسن عبد العزيز' و جيهان شرارة`و أسماء سعيد البنا' و شوقي سعد النجارَّ}

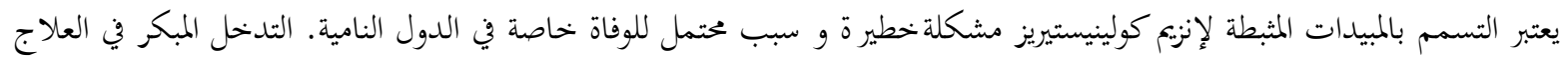

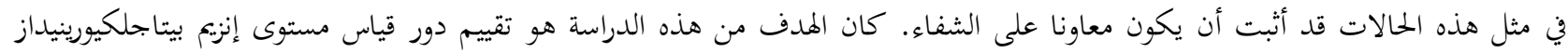

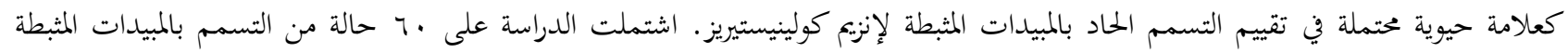

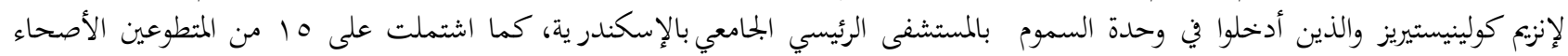

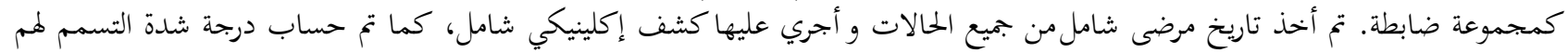

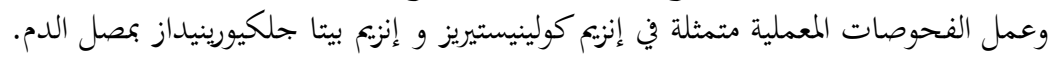

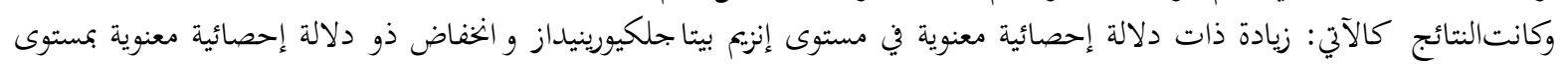

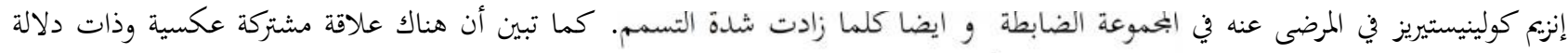

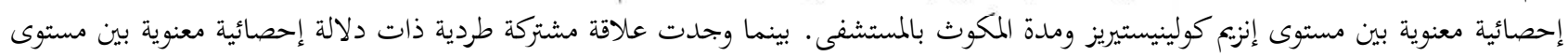

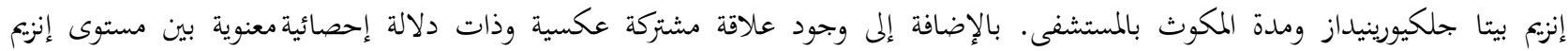

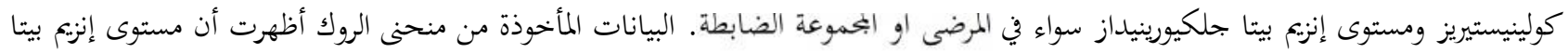

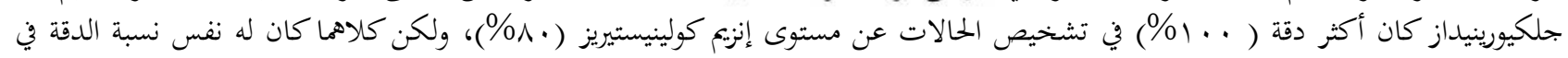
معرفة شدة التسمم أو في التنبؤ بنتائجه.

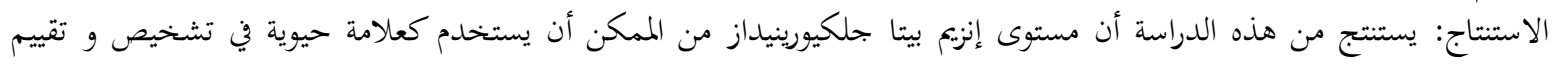
التسمم الحاد بالمبيدات المثبطة لإنزيم كولينيستيريز.

ا قسم الطب الثرعي والسموم الإكلينيكية - كلية الطب - جامعة الإسكندرية

r قسم الكيمياء الحيوية - كلية الطب - جامعة الإسكندرية r طب الطوارئ - مستشفى العامرية 